\title{
Skin microvascular reactivity in fingers of diabetic patients after combined kidney and pancreas transplantation
}

\author{
G. Jörneskog ${ }^{1}$, G. Tydén ${ }^{2}$, J. Bolinder ${ }^{3}$ and B. Fagrell ${ }^{1}$ \\ ${ }^{1}$ Department of Internal Medicine, Karolinska Institute, Karolinska Hospital, Stockholm, ${ }^{2}$ Departments of Transplantation Surgery \\ and ${ }^{3}$ Internal Medicine, Karolinska Institute, Huddinge Hospital, Huddinge, Sweden
}

Summary. Nine patients with severe late diabetic complications were investigated 2 and 38 months after successful combined kidney and pancreas transplantation. Nine healthy subjects served as controls. Blood cell velocity in single capillaries was evaluated by videophotometric capillaroscopy, and total skin microcirculation of the same area by laser Doppler fluxmetry. The measurements were performed during rest, and post-occlusive $(1 \mathrm{~min})$ reactive hyperaemia. Laser Doppler flux was also recorded during venous occlusion. The basal capillary blood cell velocity and laser Doppler flux values increased significantly $(p<0.05)$ during the observation period. The time to maximal capillary blood cell velocity during hyperaemia was prolonged 2 months after combined kidney and pancreas transplantation $(p<0.05)$, and still more so at 38 months $(p<0.05)$. The ability to decrease blood flow during venous occlusion was impaired at 2 months, and was not significantly better at reinvestigation. The results indicate a succesive increase of basal blood flow in the skin microcirculation after successful combined kidney and pancreas transplantation, but no improvement of the impaired microvascular reactivity.

Key words: Combined kidney and pancreas transplantation - Skin microvascular reactivity - Capillaroscopy Laser Doppler fluxmetry

\section{Introduction}

The main aim of pancreas transplantation in patients with diabetes mellitus is to reverse or halt the secondary complications, but whether this could be achieved by normalization of the metabolic abnormalities remains in debate. In a recent study we have shown that the skin microvascular reactivity was better in a group of diabetic patients who had undergone combined kidney and pancreas transplantation (CKPT), as compared to an equally disordered group of diabetic patients waiting for CKPT (Jörneskog et al. 1990).
The aim of the present study was to investigate if the functional microangiopathy of the skin in diabetic patients is succesively improved during the 3 first years after successful CKPT.

\section{Subjects and methods \\ Subjects. Nine (5 male, 4 female) Type 1 (insulin-dependent) diabetic patients were investigated 2 months (mean; range $0-5$ ), and 38 months (mean; range $35-43$ ) after successful CKPT. The mean age at transplantation was 38 years (range 29-45) and the mean duration of diabetes 23 years (range 17-30). They all suffered from severe late diabetic complications and all had treatment with immunosuppressive drugs. All had functioning grafts and normal blood glucose levels without exogenous insulin at investigations. Nine healthy age-matched subjects served as controls.}

Examining procedure. The skin microcirculation of the nailfold of the third or fourth finger of the left hand was studied using videophotometric capillaroscopy and laser Doppler fluxmetry. All subjects were acclimatized for $30 \mathrm{~min}$ at $23 \pm 1^{\circ} \mathrm{C}$ before measurements were performed. Smokers were asked to refrain from smoking for $2 \mathrm{~h}$ prior to the investigation. The subjects were seated with the left arm supported at heart level on a table. A miniature cuff $(2.5 \mathrm{~cm})$ was applied at the base of the investigated finger so that arterial and venous occlusions could be performed (Fagrell et al.1977). The skin temperature in the observed area was continuously recorded with an electronic thermistor (Exacon, Copenhagen, Denmark) placed immediately proximal to the nailfold under study.

Videophotometric Capillaroscopy. Nailfold capillaries of the finger were visualized on a TV-monitor by a Laborlux (Wild-Leitz, Stockholm, Sweden) microscope on which was mounted a silicon diode video camera. The image was stored on videotape for subsequent analysis. During playback of the tape, capillary blood cell velocity (CBV) was determined by a new, computerized, video-photometric, cross-correlation technique (IM-Capiflow, Kista, Sweden) (Fagrell et al. 1977; Fagrell et al. 1988). The CBV was measured in the most suitable capillary in the field of view, This has been shown to be relevant for studying skin microvascular reactivity (Östergren 1984; Richardson et al. 1985).

Laser Doppler Fluxmetry.(LD). A laser Doppler fluxmeter (Periflux Model Pf2, Perimed, Stockholm, Sweden) was used to evaluate the total skin microcirculation (Nilsson et al. 1980). The definition of flux is: velocity $x$ number of blood cells within the measured 
volume. A bandwidth of $4 \mathrm{Khz}$, and a gain of $10-100$ times were employed. The laser Doppler-probe was placed within the area immediately adjacent to the area visualized in the microscope. By this technique we also investigated the ability to decrease skin microvascular flow during venous stasis, the so-called venoarteriolar reflex (Henriksen 1976).

The following variables were measured:

1) Resting CBV (rCBV) ( $\mathrm{mm} / \mathrm{s})$, and $\mathrm{rLD}(\mathrm{mm})$

2) Peak CBV (pCBV) $(\mathrm{mm} / \mathrm{s})$ and pLD ( $\mathrm{mm})$ following release of a 1 min arterial occlusion at the finger base with a cuff pressure of $200 \mathrm{~mm} \mathrm{Hg}$.

3) Time to peak CBV (tpCBV) and tpLD during reactive hypaeremia (s).

4) The percentage decrease of LD during venous occlusion (voLD), was measured at a cuff pressure of $50 \mathrm{mmHg}$ during $30 \mathrm{~s}$.

Finger blood pressure (FBP). The systolic FBP $(\mathrm{mmHg})$ was assessed by the cuff at the base of the finger, using the LD signal as a marker for inflow distal to the cuff.

Statistical Methods. The results are presented as mean \pm SEM. To examine for statistically significant differences in the patient group, the paired Student's t-test was used. Statistical analysis between the groups was performed using the non-parametric Wilcoxon signed-rank test. A p-level of 0.05 or less was considered significant.

The study was approved by the ethics committee at Karolinska Hospital.

\section{Results}

$\mathrm{rCBV}(0.27 \pm 0.06 \mathrm{~mm} / \mathrm{s})$ and $\mathrm{rLD}(33 \pm 12 \mathrm{~mm})(\mathrm{n}=7)$ was not significantly $(\mathrm{p}=0.06)$ different 2 months after CKPT, compared to control subjects $(0.42 \pm 0.11 \mathrm{~mm} / \mathrm{s}$; $66 \pm 11 \mathrm{~mm})$. However, the values had increased significantly $(\mathrm{p}<0.05)$ at reinvestigation 38 months after CKPT $(0.54 \pm 0.12 \mathrm{~mm} / \mathrm{s} ; 67 \pm 11 \mathrm{~mm})$.

pCBV and pLD $(n=7)$ were similar 2 months after CKPT, compared to control subjects, but had increased significantly $(\mathrm{p}<0.05) 38$ months after CKPT (Fig.1,2).

tpCBV was impaired $(p<0.05) 2$ months after CKPT, and was even more prolonged $(\mathrm{p}<0.05) 38$ months after CKPT (Fig. 3).

tpLD $(\mathrm{n}=7)(8.8 \pm 0.9 \mathrm{~s})$ was similar to control subjects $(5.9 \pm 0.4 \mathrm{~s}) 2$ months after CKPT, and was unchanged $(7.9 \pm 0.9 \mathrm{~s})$ at reinvestigation 38 months after CKPT.

voLD $(\mathrm{n}=7)$ was strongly impaired $(\mathrm{p}<0.05)$ both 2 $(36 \pm 9 \%)$ and $38(48 \pm 5 \%)$ months after CKPT, compared to controls $(60 \pm 4 \%)$. However, 4 out of 5 patients with the most impaired reactivity had improved at the reinvestigation 38 months after CKPT.

The skin temperature was similar in the patients (29.2$\left.28.3 \pm 1.2-0.8^{\circ} \mathrm{C}\right)$ and the healthy subjects $\left(29.9 \pm 0.6^{\circ} \mathrm{C}\right)$ during the observation period.

The FBP was higher $(128 \pm 7.3 \mathrm{mmHg})$ in the patients $(\mathrm{p}=0.05) 2$ months after CKPT, compared to control subjects $(104 \pm 6.8 \mathrm{mmHg})$, and had decreased in all but one patient at the reinvestigation 38 months after CKPT $(111 \pm 6.8 \mathrm{mmHg}$ ).

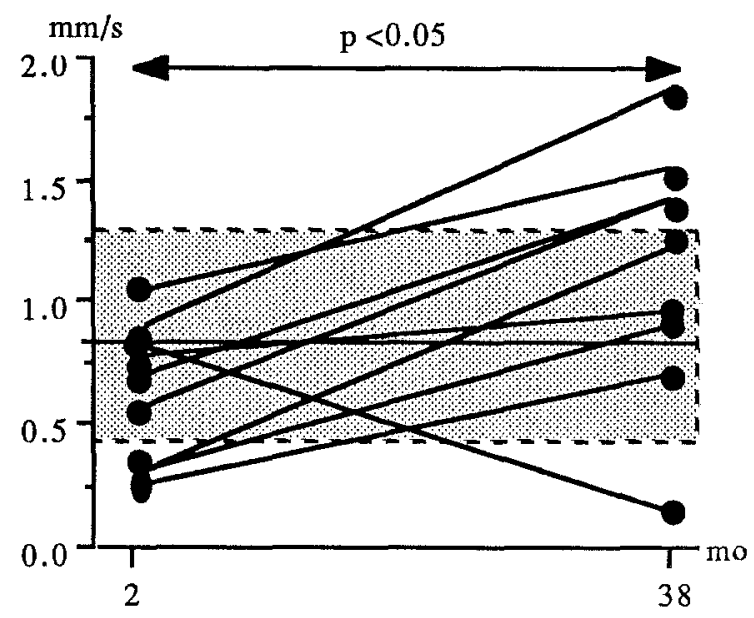

Fig. 1.pCBV 2 and 38 months after CKPT. The shadowed area shows the values obtained in the control subjects (mean \pm 1 SD).

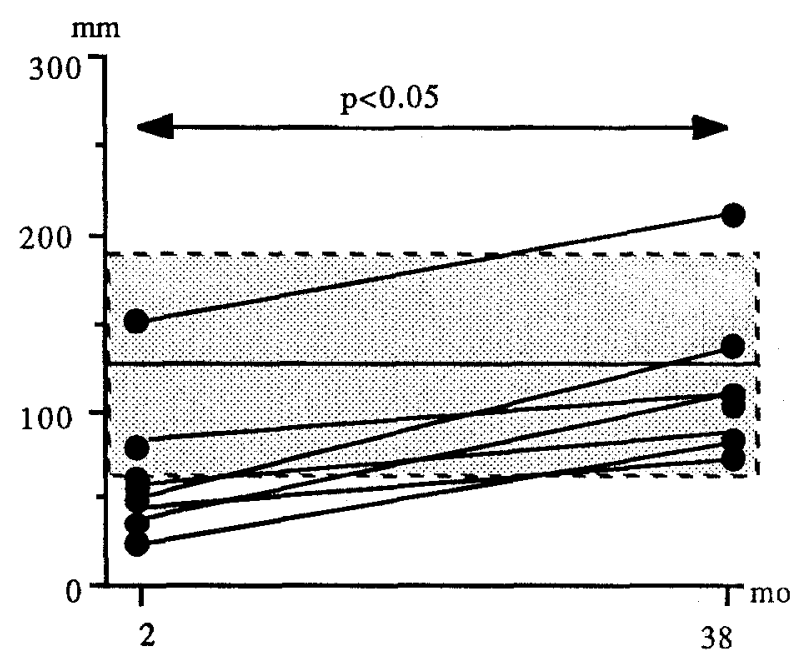

Fig.2. pLD 2 and 38 months after CKPT. The shodowed area shows the values obtained in the control subjects (meant1SD),

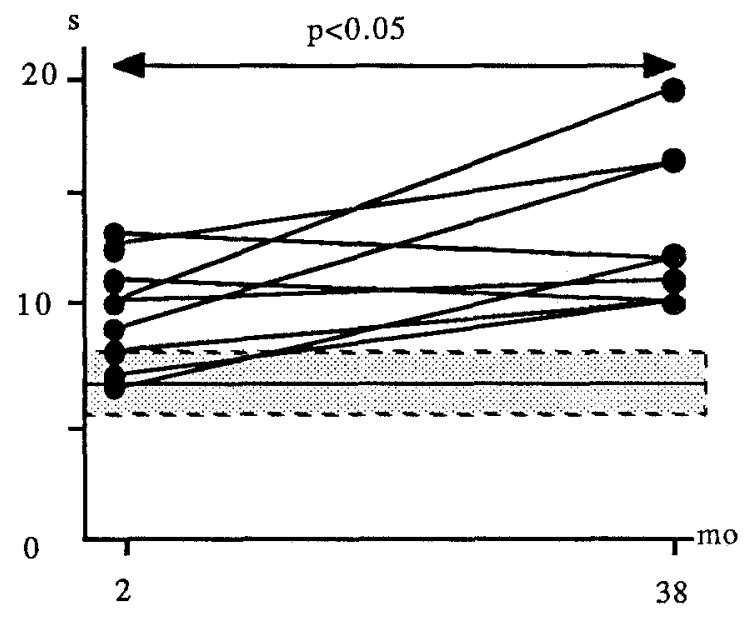

Fig.3. tpCBV 2 and 38 months after CKPT. The shadowed area shows the values obtained in the control subjects (meant1SD). 


\section{Discussion}

We know from earlier studies that the nutritional skin microcirculation of fingers in patients with late diabetic complications is decreased (Jörneskog et al. 1990), whereas the total skin microcirculation is increased (Gundersen 1974). This discrepancy between nutritional and total microcirculation has been explained by a shunting of blood through arteriovenous anastomoses (Boulton et al. 1982).

The results of the present study show an increase of both total (LD) and nutritional (CBV) skin microcirculation in diabetic patients 38 months after successful CKPT, as compared to the values obtained in connection with (2 months after) the transplantation. An increase was seen both during rest and reactive hyperaemia. The reason for this increased microcirculation could be an improvement of hemorheological factors and/or a decrease of vascular resistance. However, the treatment with strong immunosuppressive (steroids, cyclosporin) and other drugs may also have influenced the increase in microvascular flow.

A delayed time to peak during hyperaemia was found in most diabetic patients in connection with the transplantation, and the response was even more impaired at reinvestigation 38 months after CKPT. This impaired reactive hyperaemia response after the short, one min arterial occlusion is probably due to a disturbed function of the smooth muscle cells of the vessel wall (Johnson et al. 1976; Fagrell et al. 1981; Östergren et al. 1985). This is in line with the finding that patients with longstanding diabetes have structural changes of the vessel wall (Malik et al. 1989), which could also hinder the relaxation of the smooth muscle cells. The time to peak $\mathrm{CBV}$ in the present study was even more impaired at the reinvestigation 38 months after CKPT, which might indicate a progress of structural changes in spite of an improved metabolism.

The ability to decrease flow during venous stasis, the socalled venoarteriolar reflex (Henriksen 1976), was also strongly impaired in the patients at both investigations. Since the reflex is supposed to be dependent on an intact sympathetic nerve function, the impaired reactivity in the patients is most probably due to neuropathy. Even if the mean voLD was not significantly better at the reinvestigation 38 months after CKPT, 4 out of the 5 patients with the most impaired reflex had improved, which might indicate an improved nerve function in these patients. This is also in agreement with other studies (Kennedy et al. 1990), showing that the diabetic polyneuropathy can be improved after pancreas transplantation.

It may be concluded that the present study shows an increased basal blood flow in the total and nutritional skin microcirculation of fingers 38 months after CKPT, but still an impaired reactivity of the microvascular bed.

\section{References}

Boulton AJM, Scarpello JHB, Ward JD. (1982) Venous oxygenation in the diabetic neuropathic foot. Evidence of arteriovenous shunting? Diabetologia 22:6-8

Fagrell B, Eriksson S-E , Malmström S, Sjölund A. (1988) Computerized data analysis of capillary blood cell velocity. Int J Microcirc: Clin Exp 7: 276

Fagrell B, Fronek A, Intaglietta M. (1977) A microscope television system for studying flow velocity in human skin capillaries. Am J Physiol 233(2):H318-H321

Fagrell B, Fronek A, Intaglietta M. (1977) Capillary blood flow components and reactive hyperemia studies by clinical microscopy. Bibl Anat 16:112-115

Fagrell B, Fronek A, Intaglietta M. (1977) Capillary blood flow velocity during rest and postocclusive reactive hyperemia in skin area of the toes and lower leg. Bibl Anat 16:231-234

Fagrell B, Östergren J. (1981) Reactive hyperemia response in human skin capillaries after varying occlusion duration. Bibl Anat 20:692-696

Gundersen H.J.G (1974) Peripheral blood flow and metabolic control in juvenile diabetes. Diabetologia 10:225-231

Henriksen $0 .(1976)$ Local nervous mechanism in regulation of blood flow in human subcutaneous tissue. Acta Physiol Scand 97:385-391

Johnson PC, Burton KS, Henrich H, Henrich U. (1976) Effect of occlusion duration on reactive hyperemia in sartorius muscle capillaries. Am J Physiol 230 (3):715-719

Jörneskog G, Tyden G, Bolinder J, Fagrell B (1990) Does combined kidney and pancreas transplantation reverse functional diabetic microangiopathy? Transplant Int 3:167-170

Kennedy WR, Goetz FC, Najarian JS, Navarro X, Sutherland DER (1990) Effects of pancreatic transplantation on diabetic neuropathy. New Eng1. J. Med. 322:15:1031-1037

Malik RA, Newrick PG, Sharma AK, Jennings A, Ah-See AK, Mayhew TM, Jakubowski J, Boulton AJM, Ward JD (1989) Microangiopathy in human diabetic neuropathy: relationship between capillary abnormalities and the severity of neuropathy. Diabetologia 32:92-102

Nilsson GE, Tenland T, Öberg $\AA$ (1980) Evaluation of a laser Doppler flowmeter for measurement of tissue blood flow. IEEE Transactions on Biomedical Engineering, BME-27:10:597-637

Richardson D, Schwartz R, Hyde G. (1985) Effects of ischemia on capillary density and flow velocity in nailfolds of human toes. Microvascular Research $30: 80-87$

Östergren J, Fagrell B (1985) Skin capillary blood cell velocity in patients with arterial obliterative disease and polycythemia - a disturbed hyperemic response. Clin Physiol 5:35-43

Östergren J. (1984) Studies on skin capillary blood cell velocity by videophotometric capillaroscopy. Thesis. Repro Print $A B$, Stockholm

\author{
Dr. G. Jörneskog \\ Department of Medicine \\ Karolinska Hospital \\ Box 60500 \\ S-10401 Stockholm \\ Sweden
}

